\begin{tabular}{|c|c|c|}
\hline 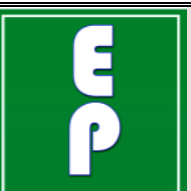 & $\begin{array}{l}\text { International Journal of Current Research } \\
\text { and Academic Review }\end{array}$ & 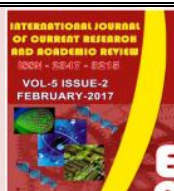 \\
\hline $\begin{array}{l}\text { EXCELLENT } \\
\text { PUBLISHERS } \\
\end{array}$ & Journal homepage: http://www.ijcrar.com & \\
\hline
\end{tabular}

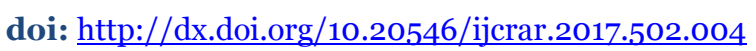

\title{
Prevalence of Traumatic Dental Injuries to Permanent Anterior Teeth among 8-12 Years Old School Children
}

\author{
Muthu Laakshmi Ganesh ${ }^{1 *}$ and Mahesh ${ }^{2}$

 \\ ${ }^{2}$ Department of Pedodontics, Saveetha Dental College, Chennai, India \\ *Corresponding author
}

\begin{abstract}
The aim of the study is to identify the prevalence of traumatic dental injuries to permanent anterior teeth among 8-12 years old school children. The objective of the study is to identify the prevalence of traumatic dental injuries to permanent anterior teeth among 8-12 years old school children through clinical examination. Traumatic dental injuries often occur in accidents or sports related injuries. They are most common during childhood. Chipped teeth are the most common traumatic dental injuries where dislodged or knocked out teeth are less frequent but more severe injuries. Treatment generally depends on type, location and severity of injury. Children of age 8-12 years were examined and if there are any traumatic dental injuries they are recorded and finally statistics is done to assess the prevalence rate. Since very less attention has been paid to traumatic dental injuries, assessing their prevalence rate have become essential.
\end{abstract}

\section{Article Info}

Accepted: 25 January 2017

Available Online: 20 February 2017

\section{Keywords}

Anterior teeth, malocclusion, over jet, prevalence, trauma.

\section{Introduction}

Traumatic dental injury (TDI) is a serious problem affecting young children and by time, its incidence will exceed that of dental caries. Dental trauma affects the different layers of the tooth structure depending on the force of trauma, and it might be followed by pulpal hyperemia, congestion and alteration in the blood flow of the pulp which is sufficient to initiate irreversible degenerative changes that may lead to pulpal necrosis. In addition, the apical vessels may be damaged enough to interfere with reparative process. On the other hand, traumatic dental injuries may be serious enough to cause maxillary and mandibular fractures (Amandeep). They occur commonly and affect approximately $20-30 \%$ of the permanent dentition worldwide that often lead to functional, aesthetic and psychological disturbances as well as significant child, parents, and dentists concerns (Bourguignon et al., 2009).

Traumatic dental injuries can be highly challenging to be treated, because clinicians often rely on dentists to treat them. However, many clinicians work in a communitybased environment where there is no dentist on call for emergencies. Treatment of traumatic dental injuries depends on many factors such as type of tooth involved (primary or permanent), nature of the injury, length of time from injury to treatment, how the tooth was cared for after the injury and some patient's factors such as age and medical fitness of the patient. The aim of the study is 
to identify the prevalence of traumatic dental injuries to permanent anterior teeth among 8-12 years old school children.

\section{Materials and Methods}

This study was conducted among 100 children aged between 8-12 years, Scheduling of survey was done by sending a prior letter of notification regarding the date and time of examination of school children. Necessary permission was obtained. Selection was done by simple random sampling. Ellis classification was used for recording injuries.

Data was obtained concerning the prevalence of dental traumatic injuries, age, gender, type of fractured teeth, occlusal relationship, terminal plane relationship and angles molar relationship (Tables 1-5).

Table.1 Number of children involved in this study

\begin{tabular}{|c|c|}
\hline NO.OF.CHILDREN & 100 \\
\hline 8 years & 19 children \\
\hline 9 years & 21 children \\
\hline 10 years & 24 children \\
\hline 11 years & 23 children \\
\hline 12 years & 13 children \\
\hline
\end{tabular}

Table.2 Gender

\begin{tabular}{|c|l|}
\hline MALES & 46 children \\
\hline FEMALES & 54 children \\
\hline
\end{tabular}

Table.3 Molar relation

\begin{tabular}{|c|c|}
\hline CLASS 1 & 84 children \\
\hline CLASS 2 & 15 children \\
\hline CLASS 3 & 1 child \\
\hline
\end{tabular}

Table.4 Percentage of students with history of trauma

\begin{tabular}{|c|c|c|}
\hline HISTORY OF TRAUMA & MALES & FEMALES \\
\hline YES & 2 & 2 \\
\hline NO & 44 & 52 \\
\hline
\end{tabular}

Table.5 Data concerning the prevalence of dental traumatic injuries

\begin{tabular}{|c|c|c|c|c|c|}
\hline AGE & GENDER & $\begin{array}{c}\text { MOLAR } \\
\text { RELATION }\end{array}$ & OVERJET & $\begin{array}{c}\text { TOOTH } \\
\text { FRACTURE }\end{array}$ & $\begin{array}{c}\text { TYPE OF } \\
\text { FRACTURE }\end{array}$ \\
\hline 9 years & Female & Class 1 & $1 \mathrm{~mm}$ & 11 & Class 1 \\
\hline 10 years & Female & Class 1 & $1.5 \mathrm{~mm}$ & 11 & Class 1 \\
\hline 11 years & Male & Class 1 & $1.5 \mathrm{~mm}$ & 21 & Class 1 \\
\hline 12 years & Male & Class 1 & $1 \mathrm{~mm}$ & 22 & Class 1 \\
\hline
\end{tabular}


Fig.1 Prevalence of traumatic dental injuries among genders in this study

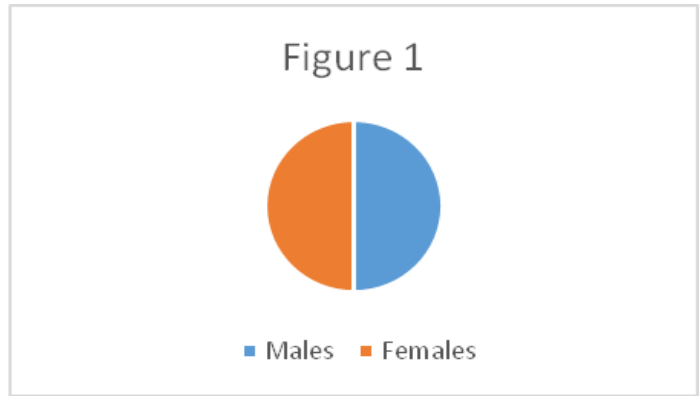

Fig.2 Molar relation among children in this study

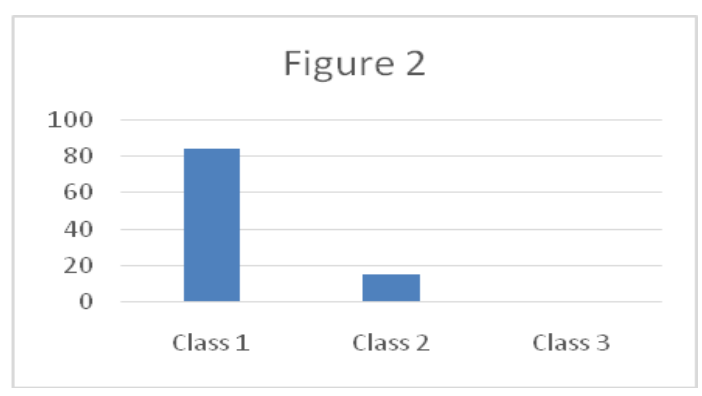

Fig.3 Commonly affected teeth in traumatic injuries in this study

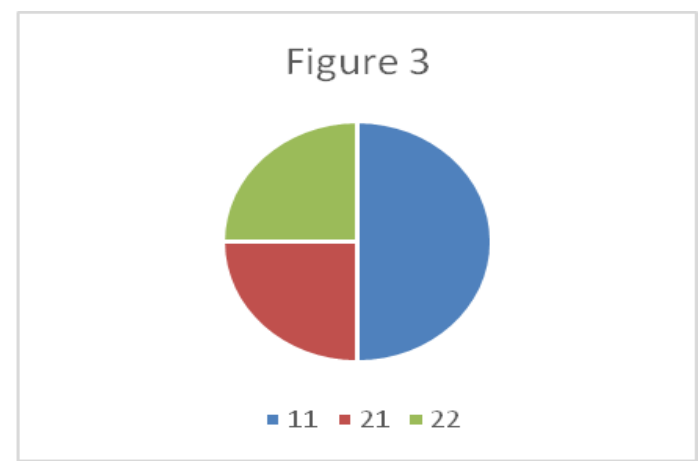

Fig.4 Prevalence of dental traumatic injuries among different age groups in this study

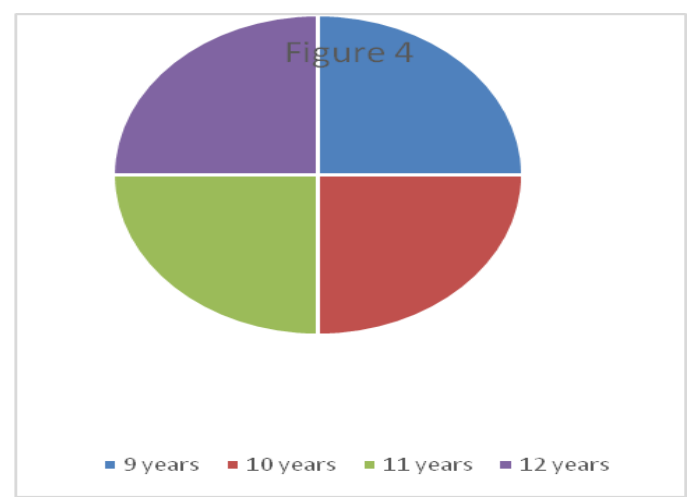




\section{Results and Discussion}

The total number of the examined students in this sample was 100.46 boys and 54 girls. The study showed that boys and girls had equal percentage of trauma $50 \%$ and $50 \%$ respectively.

The most common type of tooth injury in both genders was studied. Tooth fracture where tooth fracture was found to be higher.

The current study is a school-based study, to determine the prevalence and common types of traumatic dental injury in the anterior teeth, for a sample of school children in Chennai, the prevalence of dental trauma was reported as same $(50 \%)$ among genders.

This study was conducted among children between age groups 8 years- 12 years where all age groups are equally affected with traumatic dental injury (figure 4). This finding is in agreement with those described in the majority of epidemiological studies, which report a peak age for traumatic dental injury between nine and 12 years (O’Mullane, 1972; Jamani et al., 1991).

In most of the previous studies, males had higher prevalence of traumatic dental injuries than females (Baghdady et al., 1981). In contrast, the present result showed that both genders had similar incidence of traumatic dental injuries(figure 1). On the other hand, there was no significant difference of traumatic dental injuries between boys and girls in the study carried out in Damascus, Syria (Marcenes et al., 1999).This may be due to the small size of the study sample and difference in the age group.

In this study Maxillary anterior teeth are most commonly affected, two children had fracture in 11 and only child had fracture in 21 and 22(figure 3).11 is more commonly affected when compared 21 and 22 , which is similar to that of several studies.

In the current study, the most common type of tooth injury was found to be tooth fracture. The same result was obtained by Zerman $\mathrm{N}$ and Cavarelli $\mathrm{G}$ among the population of Italy. Also, a study carried out among 12 years old school children of South India found out that the most common type of tooth injury was uncomplicated crown fracture (Zerman, 1993). Same results were obtained in previous studies and surveys. (Altay et al., 2001; Traebert et al., 2006; Lin et al., 2008) However, luxation and complicated crown fracture was reported to be the most common cause of traumatic dental injuries in a study carried out in Saudi Arabia.

This variation in the prevalence of traumatic dental injuries can be partially attributed to the difference in the study age group, the size of study sample and populations. As well as the methods for appraise the tooth fracture.

Cases with class 1 molar relation without any malocclusion exhibited lot of traumatic injuries in this study (figure 2) where some other studies proves that children who sustained accidental damage to their maxillary incisors had increased overjet and incompetent lips at rest which is present usually in the case of class 1 division 2 and class 2 division 1.

In this study all the children have overjet less than $5 \mathrm{~mm}$ $(<5 \mathrm{~mm})$.some studies shows that subjects with increased overjet have high prevalence of dental injuries due to reduced incisor protection through lip incompetence. Therefore, the treatment of increased overjet is a necessary preventive measure for avoiding traumatic dental injuries.

\section{Conclusion}

Traumatic dental injuries seem to be serious dental public problems among school children. Accordingly, there is a great need to carry out more comprehensive studies for a larger sample size in different areas and among different age groups in order to acquire a more comprehensive representation of the dental trauma and associated risks factors and to raise the dental awareness among the students and parents.

\section{References}

Al-Majed, I., Murray, J.J., and Maguire, A. 2001. "Prevalence of dental trauma in 5-6- and 12-14year-old boys in Riyadh, Saudi Arabia, Dent. Traumatol., vol. 17, pp. 153-158.

Altay, N. and Güngör, H.C. 2001. "A retrospective study of dento-alveolar injuries of children in Ankara, Turkey, Dent. Traumatol., vol. 17, pp. 201-204.

Amandeep Chopra, Manav Lakhanpal, N.C., Rao, Nidhi Gupta, Shelja Vashisth. Traumatic Dental Injuries among 12-15-Year-Old-School Children in Panchkula.

Artun, J., Behbehani, F., Al-Jame, B., Kerosuo, H. 2005. Incisor trauma in an adolescent Arab population: 
prevalence, severity, and occlusal risk factors. Am. J. Orthod. Dentofacial Orthop., 128(3): 347-52.

Baghdady, V.S., Ghose, L.J., and Enke, H. 1981. "Traumatized anterior teeth in Iraqi and Sudanese children--a comparative study, J. Dent. Res., vol. 60, pp. 677-680.

Bourguignon, C., Sigurdsson, A. 2009. Preventive strategies for traumatic dental injuries, Dent. Clin. North Am., 53(4): 729-49.

Hamdan, M.A., Rajab, L.D. 2003. Traumatic injuries to permanent anterior teeth among 12-year-old schoolchildren in Jordan, Community Dent. Health, 20(2): 89-93.

Jamani, K.D., Fayyad, M.A. 1991. Prevalence of traumatized permanent incisors in Jordanian children, according to age, sex and socio-economic class. Odontostomatol. Trop., 14(2): 17-20.

Lin, H. and Naidoo, S. 2008. "Causes and prevalence of traumatic injuries to the permanent incisors of school children aged 10-14 years in Maseru, Lesotho." SADJ., vol. 63, pp. 152, 154-156.

Marcenes, W., Alessi, O.N., and Traebert, J. 2000. "Causes and prevalence of traumatic injuries to the permanent incisors of school children aged 12 years in Jaragua do Sul, Brazil." Int. Dent. J., vol. 50, pp. 8792.

Marcenes, W., Beiruti, N., Tayfour, D., and Issa, S. 1999. "Epidemiology of traumatic injuries to the permanent incisors of 9-12-year-old schoolchildren in Damascus, Syria." Endod. Dent. Traumatol., vol. 5, pp. 117-123.
O’Mullane, D.M. 1972. Injured permanent incisor teeth: an epidemiological study, J. Ir. Dent. Assoc., 18(4): 160173.

Rai, S., Munshi. Traumatic injuries to anterior teeth among south kanara school children- prevalence study.

Schuch, H.S., Goettems, M.L., Correa, M.B., Torriani, D.D., Demarco, F.F. 2012. Prevalence and treatment demand after traumatic dental injury in south Brazilian school children. Dent. Traumatol., 29: 297-302.

Telgi, L.R., Mohapatra, A.K., Nagrajappa, R., and Telgi, R.C. 2010. "Prevalence of traumatic dental injuries to permanent incisors among 12- year- old school children in Davangere, South India." The Chinese journal of dental research: The Official J. Scientific Section of the Chinese Stomatological Association (CSA), vol. 13, pp. 57-60.

Traebert, J., Bittencourt, D.D., Peres, K.G., Peres, M. A., de Lacerda, J.T., and Marcenes, W. 2006. "Aetiology and rates of treatment of traumatic dental injuries among 12-year-old school children in a town in southern Brazil." Dent. Traumatol., vol. 22, pp. 173-178.

Traumatic dental injuries among 8-to 12-year-old schoolchildren in Pinggu District, Beijing, China, during 2012.

Zerman, N.G. and Cavalleri. 1993. "Traumatic injuries to permanent incisors, Dental Clinic, University of Verona, Italy." Endodontic \& Dent. Traumatol., vol. 9 , pp. 61.

\section{How to cite this article:}

Muthu Laakshmi Ganesh and Mahesh. 2017. Prevalence of Traumatic Dental Injuries to Permanent Anterior Teeth among 8-12 Years Old School Children. Int.J.Curr.Res.Aca.Rev. 5 (2), 29-33.

doi: http://dx.doi.org/10.20546/ijcrar.2017.502.004 